\title{
Development of a vulnerability assessment framework to evaluate potential effects of mine water discharges from Ranger Uranium Mine, Northern Territory
}

\author{
DL Richardson BMT Australia Pty Ltd, Australia \\ G Bourke BMT Australia Pty Ltd, Australia \\ D Rissik BMT Australia Pty Ltd, Australia \\ GW Fisk BMT Australia Pty Ltd, Australia
}

M Iles Energy Resources of Australia Ltd, Australia

\begin{abstract}
Energy Resources of Australia Ltd (ERA) is planning the closure of its Ranger Uranium Mine (RUM), with decommissioning planned to conclude in 2026. One challenge for closure is understanding the potential impacts of solutes, such as magnesium, that will continue to discharge from the site via groundwater and surface water. ERA has commissioned a water quality modelling study to predict solute concentrations in the receiving environments post-closure. The authors developed a vulnerability assessment framework (VAF) to aid the interpretation of modelling results, with an initial focus on the potential effects of magnesium on environmental and cultural values (ECVs) of the mine area. This paper describes the approach used to develop the VAF and the preliminary findings of the assessment.
\end{abstract}

The VAF involved the following steps: (i) identification of ECVs, including 'key species' that are important from biodiversity and cultural perspectives, as well as important habitats and other groups; (ii) development of conceptual models of key processes and linkages with ECVs; (iii) assessment of the direct (i.e. toxicity) and indirect (i.e. food resources and habitats) sensitivity of ECVs to magnesium; (iv) assessment of the adaptive capacity of ECVs. The VAF was based on multiple information sources including ecotoxicology assessments and field studies. A multi-disciplinary scientific advisory committee provided expert guidance and input into the vulnerability assessments.

The preliminary results of this assessment indicated that all of the key species are largely insensitive to elevated magnesium concentrations ( $>10 \mathrm{mg} / \mathrm{L})$. There are several functional groups that contain species that are sensitive to magnesium ( $<3 \mathrm{mg} / \mathrm{L}$ ), especially algae and invertebrates. The resilience of these groups is a key focus of the vulnerability assessment noting many of the species have high adaptive capacity. Key knowledge gaps were identified, and work is planned for 2020-2021 to address these gaps and refine the VAF.

Keywords: magnesium, Kakadu, biodiversity, aquatic ecosystems

\section{Introduction}

\subsection{Background}

Energy Resources of Australia Ltd (ERA) operates the Ranger Uranium Mine (RUM) in the Northern Territory of Australia. The Ranger Project Area (RPA) is surrounded by Kakadu National Park (KNP) World Heritage Place and KNP Ramsar site, which are both sites of national environmental significance protected under the Commonwealth Environmental Protection and Biodiversity Conservation Act 1999. According to the current approvals, all mining and processing activities at the Ranger Mine must cease by 2021 and all decommission works must be completed by 2026 . 
High level Environmental Requirements (ERs) for the protection of people and the environment during and after mining at Ranger have been set by the Australian Government (Commonwealth of Australia 1999). The ERs specify that impacts to environmental values on the the RPA (Figure 1) are as low as reasonably achievable (ALARA) during the closure phase (ER 1.2e). An understanding of potential impacts of mine-related stressors on environmental values is therefore important to closure planning.

The release of dissolved substances from mine areas into receiving environments has been identified as a key environmental risk issue. The solute of greatest concern within RPA is magnesium. Magnesium within the receiving environment is often in the form of magnesium sulphate, predominantly derived from the weathering of magnesium dominant chlorite schists in the mine waste rock (Turner et al. 2015). Furthermore, the construction of the final rehabilitated landform of the RPA will involve large-scale use of waste rock that will generate magnesium sulphate loads in surface runoff and to shallow groundwater, which will disperse to adjacent waterways post mine closure (Energy Resources of Australia [ERA] 2014).

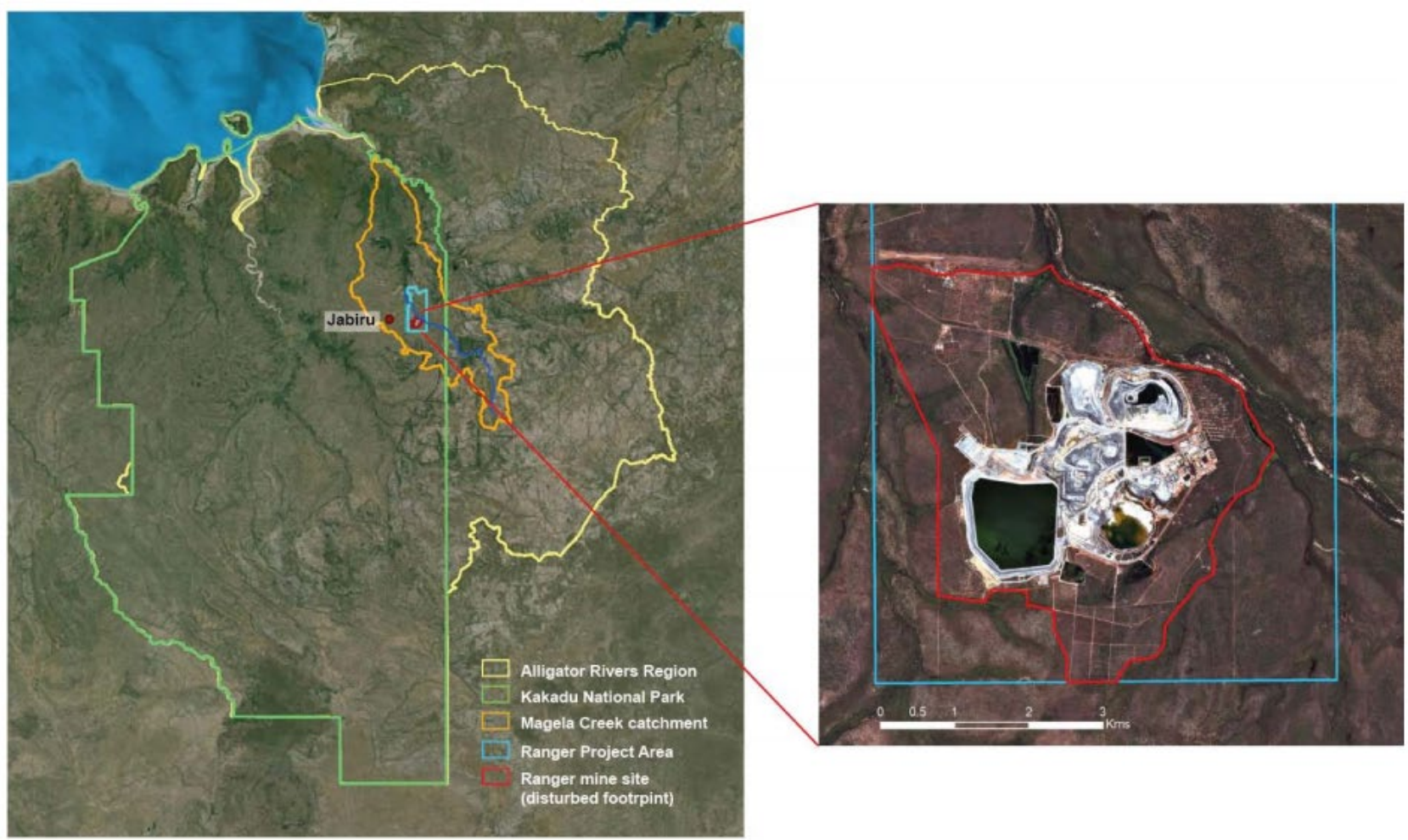

Figure 1 Ranger Project Area (RPA) and mine site (Bartolo et al. 2013)

Numerical water quality models are currently being developed to provide quantitative predictions of the concentrations of magnesium and other solutes in receiving waters during the closure phase. The Australian Government (Supervising Scientist Branch [SSB]) has also developed a water quality guideline value for magnesium based on ecotoxicological studies and field-based studies in mine-exposed waterbodies with different magnesium values. This water quality guideline value (WQGV) is based on a $99 \%$ species protection level, and therefore provides a conservative basis for determining the level at which there would be 'nochange' to the abundance of most (theoretically 99\%) species.

The ERs make specific reference to environmental attributes that must be considered in mine closure planning, including the protection of biodiversity and cultural values underpinning Kakadu Ramsar site and Kakadu World Heritage Area. The biological components (species, communities, ecosystems) that comprise these biodiversity and cultural values vary in their sensitivity to magnesium. 
From a mine closure management perspective, it is important to know for each of these biological components that if, for example, modelling predicts that the 99\% WQGV is exceeded:

- Which of these biological components will be exposed?

- Which biological components are most likely to be sensitive to magnesium?

- If biological components are compromised, what is their capacity to recover?

To determine the potential mine impacts on waters in the RPA, and how such onsite changes could indirectly affect adjacent receiving environments, an understanding of the vulnerability of environmental values is required. ERA has embarked on the Ranger Mine Closure Water Quality Framework Project (the Project) to define a process to interpret modelling results against regulatory requirements. A concurrent paper presented by Michelle lles (2019) describes the background and types of frameworks considered in the Project. This paper describes the vulnerability assessment framework process used in the Project, and the preliminary findings of assessments carried out to date.

\subsection{Vulnerability assessment framework}

To understand vulnerabilities, there is a need to consider not only sensitivity at the individual organism level, but also how this translates to vulnerability at higher organisation levels - namely the local species population, assemblage, community/habitat and/or ecosystem level - and the capacity of biota to recover. The present study describes the application of an ecological vulnerability assessment framework (VAF) to identify the vulnerabilities of aquatic biodiversity and cultural/social values to magnesium ( $\mathrm{Mg}$ ) inputs from Ranger Mine.

Ecological vulnerability assessment fills the knowledge gap that exists between laboratory and field-effects experiments on a sub-set of species or assemblages, to understanding risks to higher levels of organisation and/or to other species and species groups (De Lange et al. 2010). Ecological vulnerability assessment considers not only the direct sensitivity of organisms to a stressor, but also trophic and habitat relationships and therefore the potential for indirect flow-on effects.

Vulnerability is based on the consideration of following elements (De Lange et al. 2010; Weißhuhn et al. 2018), as shown in Figure 2:

- Level of exposure to stressors - which will be assessed by numerical modelling (not assessed in this paper).

- Sensitivities to stressors such as magnesium, both in terms of direct effects and indirect flow-on effects to habitat and or food resources. This requires consideration of the biological traits of biota, and the structural and functional relationships between the organisms, and the abiotic environment.

- Capacity to recover following a perturbation, such as exposure to a contaminant. This is also known as resilience or adaptive capacity. 


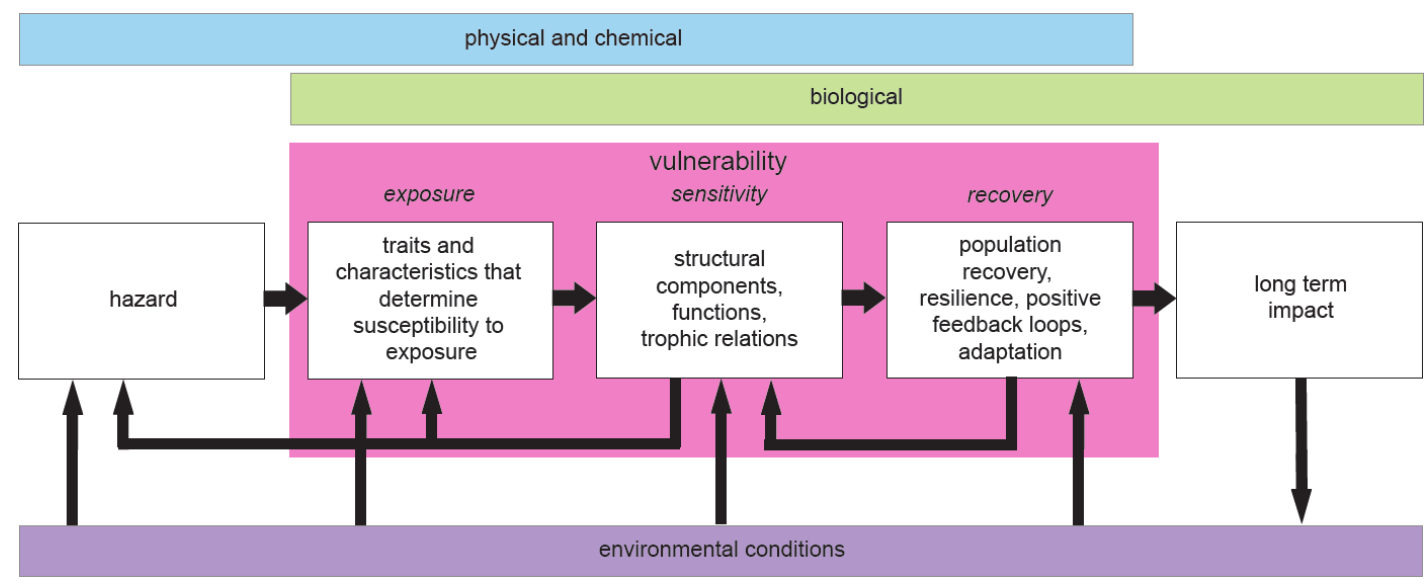

Figure 2 Modified version of the generalised ecological vulnerability assessment framework of De Lange et al. (2010)

\section{Methodology}

The VAF was developed based on the following steps.

\subsection{Define environmental values}

A central tenet of the ANZG (2018) guidelines is the identification of environmental (including cultural) values to be protected. ERs set out under Section 41 Authority for Ranger Mine provide a statutory basis for establishing management goals to protect environmental values. The ERs specify primary and secondary environmental objectives (PEOs and SEOs) that must be achieved. The PEOs and SEOs focus on maintaining and protecting four key matters: (i) world heritage attributes of Kakadu; (ii) ecological character of Kakadu National Park Ramsar wetland; (iii) The health of people; and (iv) biological diversity and ecological processes of the Alligator River Region (ARR).

A list of environmental values relevant to the above matters and waterways at and adjacent to the RPA was developed based on existing documentation, most notably world heritage attributes published at http://www.environment.gov.au/heritage/places/world/kakadu/values; and the Kakadu National Park Ramsar Wetland Ecological Character Description (BMT WBM 2010). The environmental values (EVs) incorporate elements including biophysical habitat features, local populations and assemblages of aquatic flora and fauna species, primary and secondary production of ecosystems, and cultural and human use values for waterways.

\subsection{Define components and processes that underpin environmental values}

In accordance with the Ramsar Wetland nomenclature (Department of the Environment, Water, Heritage \& the Arts [DEWHA] 2008), environmental values include both ecosystem components (i.e. physical, chemical and biological parts of a wetland) and ecosystem processes (i.e. underlying dynamic forces controlling the ecosystem). A set of ecosystem components and processes were selected based on the approach outlined in the 'National Framework and Guidance for Describing the Ecological Character of Australia's Ramsar Wetlands' (DEWHA 2008). The National Framework focuses on the identification of particularly outstanding components and processes, which are termed 'critical components' and 'critical processes'. These critical components and processes, together with ecosystem services/benefits, define the 'ecological character' of a wetland (DEWHA 2008).

Conceptual diagrams were prepared to illustrate and summarise key ecological processes operating in the study area. The process diagrams provide a basis for examining potential timing of mining releases (i.e. exposure) and key biological processes. 


\subsection{Vulnerability assessment}

\subsubsection{Define vulnerability attributes}

The vulnerability of a population, species or community is considered a function of three attributes (Foden et al. 2013, Ofori et al. 2017):

- Exposure describes the probability/extent of a hazard (disturbance or stress) occurring.

- Sensitivity is a measure of susceptibility to this hazard.

- Adaptive capacity characterises the ability to cope with the hazard and its consequences.

The exposure attribute of this vulnerability assessment is yet to be confirmed and will be based on the results of the water modelling. This vulnerability assessment investigates the vulnerability attributes of sensitivity (both direct and indirect sensitivity) and adaptive capacity (reproductive and dispersal capacity). An independent expert panel - Knowledge Management Committee (KMC) - was convened to provide expert elicitation of the sensitivities and adaptative capacity of key components and processes.

\subsubsection{Direct sensitivity}

The direct sensitivity of species and assemblages was determined based on laboratory ecotoxicity data (seven species) carried out by SSB, field-effects data collected by SSB to derive sensitive species distributions (billabong macroinvertebrate taxa, phytoplankton mesocosm experiments), and field observations of the 'maximum recorded field electrical conductivity' (EC $C_{M R F}$ ) values at which a species has been recorded. In addition to the above, monitoring studies carried out in the study area were reviewed to determine: (i) whether there was evidence of changes in aquatic assemblages or species between mine-affected waters and reference sites; and (ii) salinity conditions leading up to the survey in selected waterbodies. This provided contextual information regarding the potential effects of mine discharges on aquatic communities and functional groups. Key data sources were Corbett (1996), Corbett et al. (2004) and Wetland Research and Management ([WRM] 2010), all of which were conducted in the Magela Creek catchment, including RPA.

The direct relative sensitivity categories are shown in Table 1 . The relative sensitivity categories reflect: (i) the expected granularity of water quality modelling results; and (ii) broadly align with water quality guideline values developed by SSB for different levels of species protection.

Table $1 \quad$ Direct sensitivity criteria

\begin{tabular}{lcc}
\hline Sensitivity & Direct Mg sensitivity (units $\mathrm{mg} / \mathrm{L}$ ) & EC equivalent $(\mu \mathrm{S} / \mathrm{cm}$ )* \\
\hline Very high & $<3$ & $<42$ \\
High & $3-10$ & $42-126$ \\
Moderate & $10-30$ & $126-367$ \\
Low & $30-300$ & $367-3,620$ \\
Very low & $>300$ & $>3,620$ \\
\hline
\end{tabular}

*Based on the linear relationship between $\mathrm{EC}$ (electrical conductivity) to $\mathrm{Mg}$ in mine-affected waters $\left(r^{2}=0.97, p<0.05\right)$, as derived by Turner et al. (2015)

\subsubsection{Indirect sensitivity}

This vulnerability assessment considers indirect sensitivities through flow-on effects to each key species/functional group for dependencies on sensitive and uncommon food or habitat resources. For example, generalist species will be less sensitive than species with a specialist diet or habitat requirements, especially if those underpinning components have high sensitivity. This vulnerability component examined the food and habitat sensitivities through dietary/habitat specificity and representativeness of prey/habitat. 
The criteria for categories used to rank indirect sensitivity for each key species/functional group are shown in Table 2 (habitat) and Table 3 (food).

Table 2 Indirect sensitivity criteria - habitat

\begin{tabular}{ll}
\hline Sensitivity & Criteria \\
\hline High & $\begin{array}{l}\text { Specialist - unable to switch to other habitats; and } \\
\text { Dependent on habitats that are sensitive to } \mathrm{Mg} \text { (this refers to biophysical habitat only)*; } \\
\text { and } \\
\text { Habitat/s uncommon in the study area (i.e. restricted to a single reach or water body) and } \\
\text { ARR, and would therefore limit populations at an ARR scale }\end{array}$ \\
& $\begin{array}{l}\text { Specialist - unable to switch to other habitats; and } \\
\text { Dependent on habitats that are sensitive to } \mathrm{Mg}^{*} \text {; and } \\
\text { Hoderate } \\
\text { Hnlikely to limit populations at an ARR scale }\end{array}$ \\
Low & $\begin{array}{l}\text { Generalist - able to successfully switch to other habitats that are not sensitive to } \mathrm{Mg} \text {; } \text {; or } \\
\text { Specialist - but dependent on habitats that are insensitive to } \mathrm{Mg}^{*}\end{array}$ \\
Very low $\quad$ Generalist, not dependent on a limited habitat, even at a water body or reach scale
\end{tabular}

*Obligate dependency on biophysical habitat features rated as High to Very High sensitivity in Table 1.

Table 3 Indirect sensitivity criteria - food

\begin{tabular}{|c|c|}
\hline Sensitivity & Criteria \\
\hline \multirow{3}{*}{ High } & Specialist - unable to switch to other food resources; and \\
\hline & Dependent on food resources that are sensitive to $\mathrm{Mg}^{*}$; and \\
\hline & $\begin{array}{l}\text { Food resource/s uncommon in the study area (i.e. restricted to a single reach or water } \\
\text { body) and ARR, and would therefore limit populations at an ARR scale }\end{array}$ \\
\hline \multirow{3}{*}{ Moderate } & Specialist - unable to switch to other food resources; and \\
\hline & Dependent on food resources that are sensitive to $\mathrm{Mg}^{*}$; and \\
\hline & $\begin{array}{l}\text { Food resource/s are common in the study area (i.e. occur in multiple reaches or } \\
\text { waterbodies) and unlikely to limit populations at an ARR scale }\end{array}$ \\
\hline \multirow[t]{2}{*}{ Low } & $\begin{array}{l}\text { Generalist - able to successfully switch to other food resources that are not sensitive to } \\
\mathrm{Mg}^{*} \text {; or }\end{array}$ \\
\hline & Specialist - but dependent on food resources that are insensitive to $\mathrm{Mg}^{*}$ \\
\hline Very low & Generalist, not dependent on a limited food resource, even at a water body or reach scale \\
\hline
\end{tabular}

*Obligate dependency on food resources that are rated as High to Very High sensitivity in Table 1.

\subsubsection{Adaptive capacity - reproductive and dispersal capacity}

Adaptive capacity describes the potential for species or populations to tolerate or adapt to both short and long-term changes in environmental conditions, such as increases in Mg concentrations. The adaptive capacity considers the ability of species to recover following disturbance. Organisms that mature early and produce many offspring, especially those with a high capacity dispersal, can typically recolonise and re-populate disturbed areas quickly. Organisms that are long lived and have slow reproductive rates may still be able to rapidly recolonise disturbed areas but will take longer to recover if their populations are impacted (i.e. mortality of individuals). 
The traits used to assess adaptive capacity in this assessment were reproductive capacity and dispersal/recolonisation capacity. The criteria for ranking reproductive capacity and dispersal capacity are presented in Tables 4 and 5, respectively.

Table 4 Adaptive capacity criteria - reproductive capacity

\begin{tabular}{|c|c|}
\hline $\begin{array}{l}\text { Reproductive } \\
\text { capacity }\end{array}$ & Criteria \\
\hline Very low & $\begin{array}{l}\text { These are organisms with a low net reproductive rate (i.e. few offspring produced } \\
\text { by an individual during its lifetime). Long generation time }>5 \text { years) and produces } \\
\text { few offspring (one or fewer clutches per annum, clutch size is a few individuals) }\end{array}$ \\
\hline Low to Moderate* & Long generation time ( $\geq 5$ years) and produces many offspring \\
\hline Low to Moderate* & Short to moderate generation time ( $\leq 5$ years) and produces few offspring \\
\hline High & $\begin{array}{l}\text { Short generation time ( }<5 \text { years, but typically }<1 \text { year) and produces many } \\
\text { offspring }\end{array}$ \\
\hline
\end{tabular}

*Note 'Low' and 'Moderate' categories for Reproductive Capacity are interchangeable.

Table $5 \quad$ Adaptive capacity criteria - dispersal and recolonisation capacity

\begin{tabular}{ll}
\hline Dispersal capacity & Criteria \\
\hline Very low & $\begin{array}{l}\text { Seasonally dependant movement (i.e. species with water-based dispersal modes } \\
\text { that require the interconnectedness of waterbodies in wet season for dispersal), } \\
\text { disperses/recolonises small distances }(<10 \mathrm{~km}) \text { and highly restricted, sessile and } \\
\text { site attached }\end{array}$ \\
Low to Moderate* & $\begin{array}{l}\text { Non-seasonally dependant movement (i.e. species with terrestrial or air-based } \\
\text { dispersal modes) and disperses/recolonises small distances }(<10 \mathrm{~km})\end{array}$ \\
\hline Low to Moderate* & $\begin{array}{l}\text { Seasonally dependant movement (i.e. species with water-based dispersal modes } \\
\text { that require the interconnectedness of waterbodies in wet season for dispersal) } \\
\text { and disperses/recolonises large distances ( }>10 \mathrm{~km})\end{array}$ \\
\hline High & $\begin{array}{l}\text { Non-seasonally dependant movement (i.e. species with terrestrial or air-based } \\
\text { dispersal modes) and disperses/recolonises large distances }(>10 \mathrm{~km})\end{array}$ \\
\hline
\end{tabular}

*Note 'Low' and 'Moderate' categories for Dispersal Capacity are interchangeable.

\subsubsection{Scoring}

The scoring of sensitivity and adaptive capacity was undertaken independently by the authors and the KMC. Where there was insufficient or conflicting data available, scorers were able to select multiple categories or provide a range of possible categories to show variability within an indicator.

The authors also provided a Confidence Rating for each key species/functional group based on data quality. The Confidence Rating was based on the following criteria:

- High - component has been well studied in ARR, high confidence (based on published literature, strong evidence or local studies).

- Moderate - component has been studied in ARR, limitations in existing information base, but moderate confidence based on informed expert opinion (based on credible data and information, strong expert judgement). Moderate confidence also included a well-studied component elsewhere coupled with judgement if it is applicable to the study area.

- Low - component poorly studied in ARR, informed expert opinion (based on expert opinion, limited available studies). 


\section{Preliminary findings}

\subsection{Defining key hydrological processes and ecosystem dynamics}

Hydrological processes fundamentally govern the character and resilience of freshwater ecosystems in the Kakadu region, including Magela Creek (BMT WBM 2010; Douglas et al. 2005; Pettit et al. 2011; Warfe et al. 2011). While fine scale temporal patterns (timing, duration, frequency) and magnitude of rainfall events may vary from year to year, seasonal patterns in the physio-chemical and biological character of waters broadly follow predicable flood-drought cycles. Wet season flows increase aquatic habitat extent and lateral and longitudinal habitat connectivity, leading to an explosion of aquatic ecosystem productivity (Figure 3). Most aquatic species have peak reproduction, recruitment and biomass during the wet season (e.g. Bishop et al. 2001; Douglas et al. 2005, Warfe et al. 2011). Flows are also key drivers of physical (geomorphological) and biological processes that control the structure of aquatic habitats.

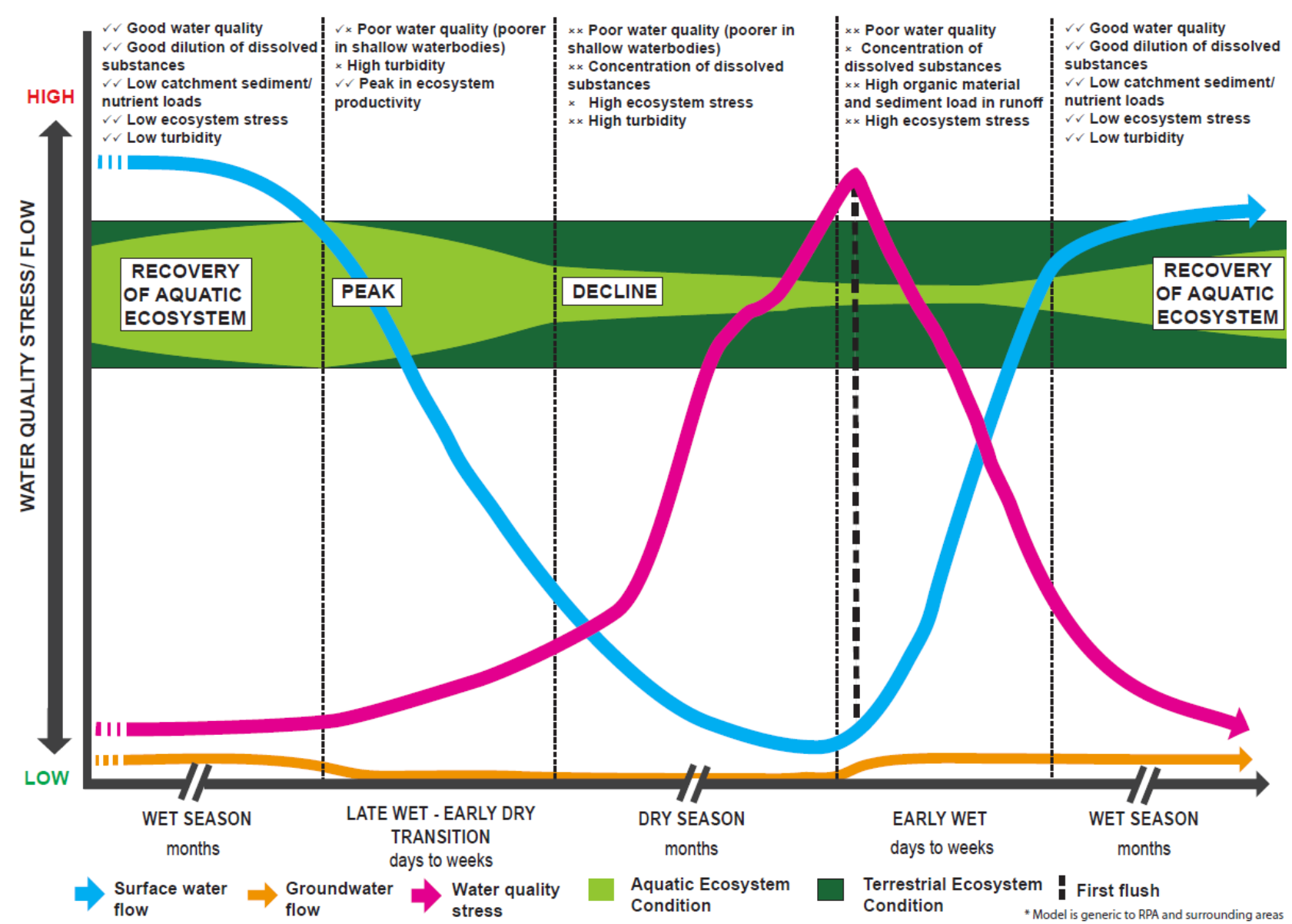

Figure 3 Generalised conceptual model of seasonal changes to flow regimes, water quality stress and aquatic ecosystem condition in the Ranger Project Area (RPA) and surrounds

During the dry season aquatic habitats retract and waterbodies become disconnected, although in wetter years, substantial floodplain areas of the Magela Creek catchment can remain inundated into the dry season (Bunn et al. 2015). The dry season retraction in habitat and food resource availability reduces overall aquatic ecosystem biomass, and top-down biological interactions (predation, competition) become increasing important ecosystem controls. Water quality deterioration can lead to significant ecosystem stress, especially in shallow waterbodies (Warfe et al. 2011). Deep permanent billabongs (such as Mudjinberri Billabong) represent critically important dry season refugia, and generally have good water quality year-round.

Many components, especially lower trophic levels, display great variability over a range of temporal and spatial scales. Phytoplankton assemblages in billabongs are remarkedly stochastic, displaying rapid 
successional changes and species turnover at timescales measured in hours, and a high level of patchiness at spatial scales measured at $10 \mathrm{~s}$ to $100 \mathrm{~s}$ of $\mathrm{cm}$ (Kessell \& Tyler 1982). Periphyton (attached algae) also vary greatly over time in terms of biomass (Ward et al. 2016), but little is known of the population dynamics of different taxonomic groups. Most invertebrate species are short-lived (measured in months) and assemblage structure varies seasonally and from year to year, never reaching a predictable assemblage of species (Humphrey \& Chandler 2018). It is therefore not meaningful to consider vulnerability at the species level for these lower order taxa.

There findings have several important implications from a vulnerability assessment context:

- Exposure:

- Wet season - high flows and massive water volumes result in significant dilution and advection of dissolved substances, both natural and mine derived. Floodplain inundation greatly expands aquatic habitat extent, therefore minimising the risk of solutes in mine discharges creating a chemical barrier to fauna movements. Low risk of water quality impacts to aquatic ecosystems.

- Late wet/dry season transition - this is a period when water levels and declining and aquatic biota are moving from the floodplain to dry season refuges. Lower flows reduce opportunities for dilution/dispersion of dissolved substances. As defined waterways will now represent the main aquatic fauna movement corridor, saline water entering waterways could create chemical barrier for sensitive aquatic biota.

- Dry season - surface water flows cease during this period, and groundwater flow to creek systems also ends around at the same time (J. Pickens Intera, personal communication, August $11,2018)$. This is a period of high natural water quality stress to aquatic ecosystems, especially shallow billabongs and residual pools in creeks. Evaporation results in concentration of dissolved substances, and in shallow waterbodies, high water temperatures and organic loading reduce dissolved oxygen concentrations. Mine-derived $\mathrm{Mg}$ loading from the preceding flow periods could lead to additional ecosystem stress.

- Dry to wet season transition - poor ambient water quality in the first flush. This natural water quality stress is coincident with a period of increased biological activity, especially post-first flush. The capacity for flows to dilute and advect dissolved substances is dependent on the timing and size of flows.

- Resilience:

- Aquatic species require strategies to adjust to shifts in food and habitat resource availability.

- Aquatic species require adaptations that enable rapid recovery following seasonal habitat perturbations.

\subsection{Vulnerability assessment}

\subsubsection{Direct sensitivity}

The direct sensitivity of species and assemblages was determined with reference to laboratory ecotoxicity data (seven species) and field-effects data (billabong macroinvertebrate taxa, phytoplankton mesocosm experiments), and inferred based on field observations of maximum recorded electrical conductivity values (a proxy for Mg sensitivity) and monitoring studies in the Alligator Rivers Region.

Preliminary results suggest that none of the key species were considered to have very high $(<42 \mu \mathrm{S} / \mathrm{cm})$ direct salt sensitivity. In terms of assemblages, field-effects studies conducted by SSB demonstrate that $1 \%$ of billabong macroinvertebrate taxa have very high direct sensitivity. Some species of algae are also known to have very high to high sensitivity. Other groups (i.e. macrophytes, riparian and floodplain plants, vertebrates) are expected to have moderate to very low direct $\mathrm{Mg}$ sensitivity, as inferred from field studies summarised in Table 1 and other sources. 


\subsubsection{Dependency on sensitive habitats or food resources}

Sensitivity also considers flow-on effects to species associated with changes to food and habitat resources. Generalist species will be less sensitive than species with a specialist diet or habitat requirements, especially if those underpinning components have high sensitivity.

\subsubsection{Dietary specificity and representativeness of prey}

Figure 4 is a food web for waterways in the RPA and surrounds. Because most fish and other aquatic vertebrates feed on a broad range of items, food-webs are short, diffuse, and highly inter-connected (Douglas et al. 2005).

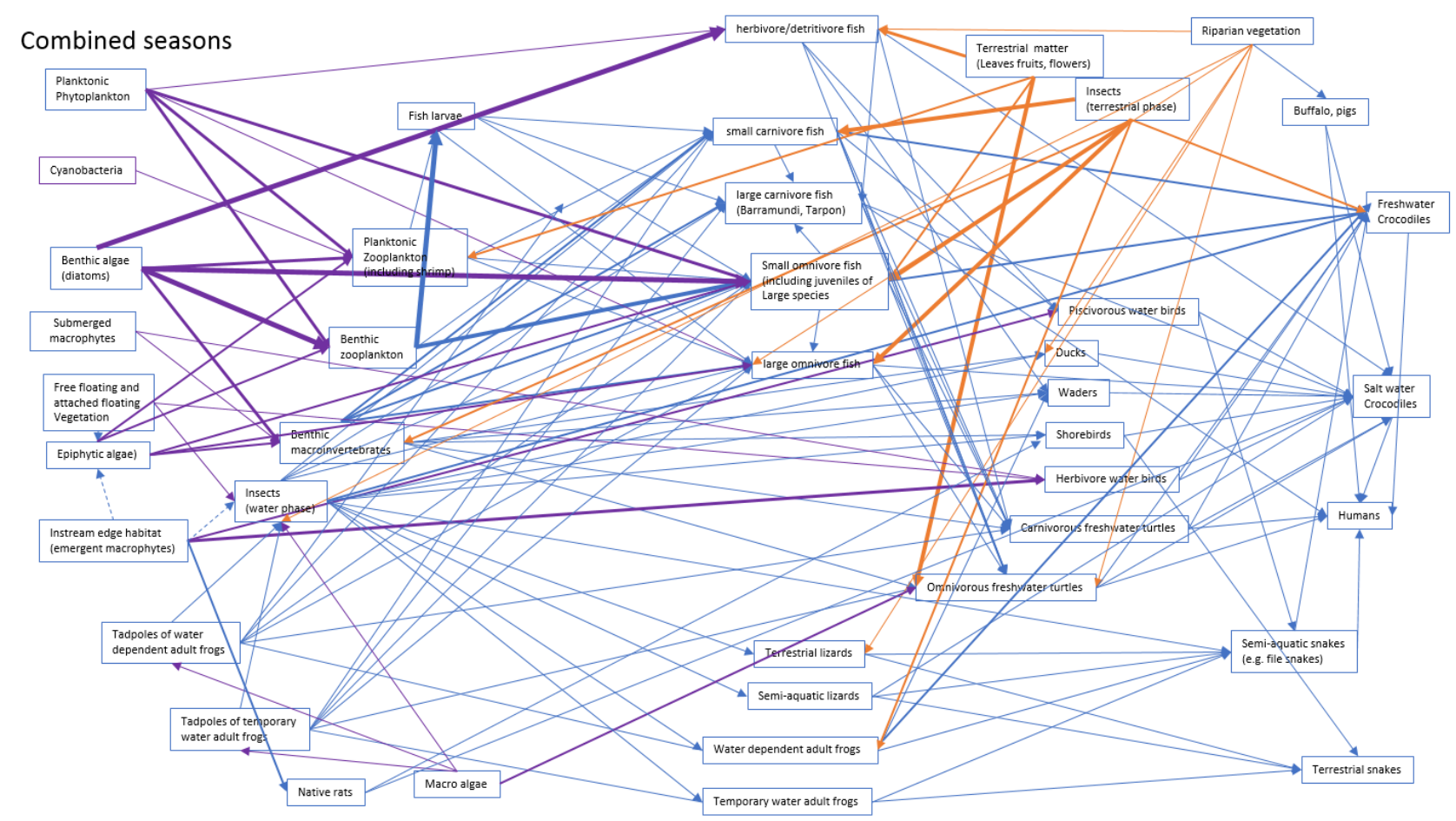

Figure 4 Food web for billabongs in the Ranger Project Area (RPA) and surrounds

All of the key fauna species have generally plastic diets, a requirement for living in environments with fluctuating food resource availability as described above. A notable exception is the magpie goose, which is abundant and common year-round in the Kakadu region and feeds exclusively on aquatic macrophyte species, which are resilient to water quality stress.

In a vulnerability context, preliminary results suggest that vertebrate fauna are considered to have low sensitivity to food resource limitation.

\subsubsection{Habitat specificity and representativeness}

Specialist species that rely on an uncommon habitat type will be more sensitive than generalist species. There is a good understanding of the habitat requirements of most vertebrates and flowering plants, whereas other groups are less well studied.

Preliminary results suggest that no species are known or likely to be restricted to a single water body. In this regard, while creeks differ to billabongs, aquatic habitat types found in the RPA and surrounds have a similar physical, physio-chemical and ecological character, and most are common and well represented at a Magela Creek catchment scale. Due to the high degree of habitat connectivity, it is highly unlikely that isolated populations of species restricted to a few sites (as occurs in springs in the escarpment lands) exist in the RPA and surrounds. Species likely to be most sensitive from a habitat limitation perspective are those species that 
critically depend on Mudjinberri Billabong as a dry season refugia, and fish species that depend on habitats in the stone country and must migrate through the study area to complete their lifecycle.

\subsubsection{Adaptability}

The adaptive capacity considers:

- The capacity of species to recover following disturbance (reproductive and dispersal capacity).

- The capacity for biota to acclimatise to the change in environmental conditions.

To exist in ephemeral environments that typically dry annually, resident species must have traits that allow rapid recolonisation following disturbance. Short-lived species (algae, most invertebrates and macrophytes) typically have high reproductive output, high dispersal capacity and/or have strategies to survive desiccation (e.g. burrowing, resting spores/eggs etc.). Vertebrate species are highly mobile and therefore have high dispersal capacity, and therefore have the ability to colonise from other areas. These results suggest that a high degree of adaptative capacity is a necessary condition for living in such highly dynamic environments. However, many vertebrate species are long lived and have low reproductive output (e.g. crocodiles, birds etc.), and their populations are more vulnerable to disturbance should mortality occur.

The capacity for biota to acclimatise to the change in environmental conditions depends on the duration, frequency and intensity of disturbance, and the biology of the organism. Macroinvertebrate assemblages in Coonjimba Billabong, which has been exposed to high Mg (and other mine contaminants of potential concern) for many years, are rich and abundant, and appear to be showing signs of acclimation. There is insufficient data at this stage to determine acclimation capacity of different groups.

\subsubsection{Summary of vulnerability}

Preliminary results suggest that EVs can be assigned to three broad vulnerability groupings:

- Algae and most invertebrates. These groups form the base of food-webs and contain a large number of species ( $>100$ species). These taxa have the following vulnerability characteristics:

- Direct sensitivity - great variability, ranging from highly sensitive to $\mathrm{Mg}$ (i.e. mortality at $\mathrm{Mg}$ concentration $<3 \mathrm{mg} / \mathrm{L}$ ), whereas others are known to occur in sea water (low sensitivity). Sensitive algae and invertebrate species are the most vulnerable groups should the $99 \%$ WQGV be exceeded.

- Indirect sensitivity - these groups typically have low to moderate indirect sensitivity (preference for particular water types, but none are known to be restricted or otherwise critically dependent on a single water body.

- Adaptive capacity - these groups have high adaptive capacity. They have characteristically high turnover and reproductive rates, and can rapidly recolonise following disturbance. Any shortterm change in $\mathrm{Mg}$ is highly unlikely to result in long-term impacts to these groups, but longterm changes in $\mathrm{Mg}$ are expected to result in changes to community structure (e.g. loss of sensitive species, replacement by Mg tolerant species).

- Aquatic macrophytes have the following vulnerability characteristics:

- Direct sensitivity - these groups have characteristically low direct $\mathrm{Mg}$ sensitivity (i.e. most are known or highly likely to tolerate $\mathrm{Mg}$ concentrations $>20 \mathrm{mg} / \mathrm{L}$ ).

- Indirect sensitivity - all species have a wide geographic distribution and no species have populations that are critically dependent on an individual water body or stream reach. These species are therefore considered to have low to moderate indirect $\mathrm{Mg}$ sensitivity.

- Adaptative capacity - the capacity to recover varies among species. Most macrophytes are subject to seasonal drying and therefore have adaptations that allow rapid recovery, i.e. high 
adaptability. Riparian trees have longer recovery times. These groups represent critical biophysical habitat features that underpin the biodiversity values of the ARR.

- Vertebrate fauna species (fish, reptiles, mammals, frogs and birds), mussels and freshwater prawns. These groups encompass all of the Key Fauna Species Groups and have the following vulnerability characteristics:

- Direct sensitivity - these groups have characteristically low direct Mg sensitivity (i.e. most are known or highly likely to tolerate $\mathrm{Mg}$ concentrations $>20 \mathrm{mg} / \mathrm{L}$ ).

- Indirect sensitivity - most species are generalist feeders that can adjust their diet depending on food resource availability, although some species have clear dietary preference, e.g. magpie goose preference for Eleocharis. Most species have a wide geographic distribution and no species have populations that are known to be critically dependent on a particular water body or stream reach. These species are therefore considered to have low to moderate indirect $\mathrm{Mg}$ sensitivity.

- Adaptative capacity - all species are highly mobile and capable of evading stressors and/or rapidly recolonising from adjacent waterbodies following disturbance. Generation times are variable, but typically measured in years.

\subsubsection{Exposure}

Exposure represents the final element of vulnerability assessment. For short-term exposure periods (measured in hours to 10s of hours), sensitivity increases with increasing exposure. The response of biota to longer periods of exposure is more complex, and as noted previously, acclimation can occur in response to long-term exposure to elevated magnesium (measured in years). Together with duration and intensity of exposure, biological responses will also depend on frequency of exposure events, and there is little available information in this regard.

Timing of exposure is also an important determinant of sensitivity, especially to key ecological processes. Many critical ecological processes are timed to occur during the wet season, coincident with flooding when maximum dilution of dissolved substances will occur. During the dry season aquatic ecosystems are under significant natural water quality stress. Based on preliminary hydrological modelling carried out by Intera, it is expected that the groundwater inputs from the mine, which is the main pathway of $\mathrm{Mg}$ loads from the mine area, is unlikely to affect surface waterbodies during the dry season.

Water quality modelling will be carried out as part of a separate exercise to determine the exposure of receiving environments to $\mathrm{Mg}$ and other mine-derived pollutants.

\section{$4 \quad$ Knowledge gaps}

Further research priorities to better understand and define vulnerability are as follows:

- Whole of ecosystem assessment to determine characteristics of aquatic ecosystems at sites with different Mg exposures.

- Experimental work to assess the effects of $\mathrm{Mg}$ on fish movement patterns, attached algae, phytoplankton and riparian vegetation.

\section{Conclusion}

The VAF provides an understanding of the vulnerability of environmental values, which is important for determining the potential mine impacts on waters in the RPA, and how such onsite changes could indirectly affect adjacent receiving environments. Model outputs will be assessed for each water body type (creek, billabong etc.) to be able to better understand and communicate to Government and stakeholders about the 
extent, severity and duration of predicted impacts to environmental values. As such, this assessment will provide guidance to how ALARA is being met on the RPA site.

\section{Acknowledgement}

This report was prepared by BMT EA under contract to Energy Resources Australia. The project team wish to express their thanks to the members of the Knowledge Management Committee formed for the project for their assistance and inputs into the report, namely Dr Bruce Chessman (Independent Consultant), Dr Graeme Batley and Dr Peter Bayliss (CSIRO), Professor Max Finlayson (Charles Sturt University), Professor Mark Taylor (Macquarie University), Dr Chris Brady (Northern Land Council), Dr Chris Humphrey, Dr Andrew Hartford (Environmental Research Institute of the Supervising Scientist) and Kyla Valdron Clark (Independent Consultant). BMT is especially grateful to Dr Chris Humphrey, Dr Andrew Hartford and Kyla Valdron Clark for the provision of raw data and helpful comments on draft reports.

Photos that appear in the report are supplied by BMT or other organisations where noted. Figures that have been reproduced (without modification) from other sources have been referenced accordingly.

The team acknowledges the Mirrar, the traditional owners of the lands that form the Ranger Project Area.

\section{References}

ANZG 2018, Australian and New Zealand Guidelines for Fresh and Marine Water Quality, Australian and New Zealand Governments and Australian State and Territory Governments, Canberra, www.waterquality.gov.au/anz-guidelines

Bartolo, R, Paulka, S, van Dam, R, lles, S \&Harford, A 2013, Rehabilitation and Closure Ecological Risk Assessment for Ranger Uranium Mine: Documentation of Initial Problem Formulation Activities, Internal Report 624, November, Supervising Scientist, Darwin.

Bishop, KA, Allen, SA, Pollard, DA \& Cook, MG 2001, Ecological Studies on the Freshwater Fishes of the Alligator Rivers Region, Northern Territory: Autecology, Supervising Scientist Report 145, Supervising Scientist, Darwin.

BMT WBM 2010, Ecological Character Description for Kakadu National Park Ramsar Site, prepared for the Australian Government Department of Sustainability, Environment, Water, Population and Communities.

Bunn, S, Ward, D, Crook, D, Jardine, T, Adame, F, Pettit, N, Douglas, M, Valdez, D \& Kyne, P 2015, Tropical Floodplain Food Webs Connectivity and Hotspots: Final report, Charles Darwin University, Darwin.

Commonwealth of Australia 1999, Environmental Requirements of the Commonwealth of Australia for the Operation of Ranger Uranium Mine, viewed 1 April 2019, https://www.environment.gov.au/system/files/resources/9cc1f5c4-18ad-4604-93bfe9efd8390ee0/files/ranger-ers.pdf

Corbett, L 1996, Aquatic studies at Ranger Mine: a Whole-ecosystem Approach: Final Report, CSIRO Division of Wildlife and Ecology, Darwin for ERA Environmental Services, Darwin.

Corbett, L, Batterham, R \& Zimmermann, A 2004, Aquatic Studies at Ranger Mine: Whole-Ecosystem Monitoring - Round 2: Final Report, for ERA Ranger Mine, EWL Sciences Pty Ltd.

De Lange, H, Sala, S, Vighi, M \& Fabera, JH 2010, 'Ecological vulnerability in risk assessment - A review and perspectives', Science of the Total Environment, vol. 408, pp. 3871-3879.

Department of the Environment, Water, Heritage \& the Arts 2008, National Framework and Guidance for Describing the Ecological Character of Australia's Ramsar Wetlands, Module 2 of the National Guidelines for Ramsar Wetlands-Implementing the Ramsar Convention in Australia, Australian Government Department of the Environment, Water, Heritage and the Arts, Canberra.

Douglas, MM, Bunn, SE \& Davies, PM 2005, 'River and wetland food webs in Australia's wet-dry tropics: general principles and implications for management', Marine and Freshwater Research, vol. 56, pp. 329-342.

Energy Resources of Australia 2014, Ranger Closure Criteria: Record of Development by the Closure Criteria Working Group, 22/07/2014, Energy Resources of Australia, draft.

Foden, WB, Butchart, SHM, Stuart, SN, Vié, JC, Akçakaya, HR, Angulo, A, ... Mace, GM 2013, 'Identifying the world's most climate change vulnerable species: a systematic trait-based assessment of all birds, amphibians and corals', PLOS ONE, vol. 8, no. 6, e65427.

Humphrey, C \& Chandler, L 2018, Use of Field-effects Information to Inform Surface Water Guideline Values for Magnesium Sulfate in Magela Creek (draft), Supervising Scientist, Report 213, Darwin.

lles, M 2019, 'How can frameworks inform water quality objectives for the closure of the Ranger mine?', in AB Fourie \& M Tibbett (eds), Proceedings of the 13th International Conference on Mine Closure, Australian Centre for Geomechanics, Perth, pp. 437-446.

Kessell, JA \& Tyler, PA 1982, Phytoplankton Populations of the Magela Creek System, Alligators Creek Region and Northern Territory, University of Tasmania, Department of Botany, Tasmania, Supervising Scientist.

Ofori, BY, Stow, AJ, Baumgartner, JB \& Beaumont, LJ 2017, 'Influence of adaptive capacity on the outcome of climate change vulnerability assessment', Scientific Reports, vol. 7, 12979. 
Pettit, NE, Bayliss, P, Davies, PM, Hamilton, K, Warfe, DM, Bunn, SE \& Douglas, MM 2011, 'Seasonal contrasts in carbon resources and ecological processes on a tropical floodplain, Freshwater Biology, vol. 56, pp. 1047-1064.

Turner, K, Tayler, K \& Tyrrell, JWR 2015, Revised Ranger Mine Water Quality Objectives for Magela Creek and Gulungul Creek, Supervising Scientist, Internal Report 638, Darwin.

Ward, D, Pettit, NE, Adame, F, Douglas, MM, Setterfield, SA \& Bunn, S 2016, 'Seasonal spatial dynamics of floodplain macrophyte and periphyton abundance in the Alligator Rivers region (Kakadu) of northern Australia', Ecohydrology, vol. 9, no. 8, pp. 1675-1686.

Weißhuhn, P, Müller, R \& Wiggering, H 2018, 'Ecosystem vulnerability review: proposal of an interdisciplinary ecosystem assessment approach', Environmental Management, vol. 61, pp. 904-915.

Warfe, DM, Pettit, NE, Davies, PM, Pusey, BJ, Hamilton, SK, Bayliss, P... Halliday, I 2011, 'The 'wet-dry' in the wet-dry tropics drives river ecosystem structure and processes in northern Australia', Freshwater Biology, vol. 56, pp. 2169-2195.

Wetland Research and Management 2010, Aquatic Fauna Assessments 2009: Creeks and Billabongs Downstream of Ranger Uranium Mine, prepared for EWL Sciences Pty Ltd. 